\title{
Nutritional and Nanotechnological Modulators of Microglia
}

\author{
Dusica Maysinger* and Issan Zhang \\ Department of Pharmacology and Therapeutics, McGill University, Montreal, QC, Canada
}

Microglia are the essential responders to alimentary, pharmacological, and nanotechnological immunomodulators. These neural cells play multiple roles as surveyors, sculptors, and guardians of essential parts of complex neural circuitries. Microglia can play dual roles in the central nervous system; they can be deleterious and/or protective. The immunomodulatory effects of alimentary components, gut microbiota, and nanotechnological products have been investigated in microglia at the single-cell level and in vivo using intravital imaging approaches, and different biochemical assays. This review highlights some of the emerging questions and topics from studies involving alimentation, microbiota, nanotechnological products, and associated problems in this area of research. Some of the advantages and limitations of in vitro and in vivo models used to study the neuromodulatory effects of these factors, as well as the merits and pitfalls of intravital

\section{OPEN ACCESS}

Edited by:

Saparna Pai,

Centenary Institute, Australia

Reviewed by:

Ihsan Gursel,

Bilkent University, Turkey

Pavan Bhargava,

Johns Hopkins University

School of Medicine, USA

*Correspondence:

Dusica Maysinger

dusica.maysinger@mcgill.ca

Specialty section:

This article was submitted to

Multiple Sclerosis and

Neuroimmunology,

a section of the journal

Frontiers in Immunology

Received: 17 March 2016

Accepted: 27 June 2016

Published: 15 July 2016

Citation:

Maysinger D and Zhang I (2016)

Nutritional and Nanotechnological

Modulators of Microglia.

Front. Immunol. 7:270.

doi: 10.3389/fimmu.2016.00270 imaging modalities employed are presented.

Keywords: neuroinflammation, microglia, immunomodulation, nutrition, microbiota-gut-brain axis, intravital imaging, nanodelivery systems, nanomedicine

\section{INTRODUCTION}

Neuroinflammation has been considered a detrimental factor in many neurodegenerative diseases (e.g., Alzheimer's disease, Parkinson's disease, and multiple sclerosis) (1-4). As the resident immune cells of the brain, microglia play a central role in neuroinflammatory processes. Traditionally, microglia were considered seminal contributors to neurodegeneration associated with neuroinflammation $(5,6)$. However, this view is gradually changing (7). Under normal conditions, microglia survey the brain and perform essential housekeeping functions, ranging from the scavenging of cellular debris to synaptic remodeling, but they switch from "surveyors" to "attackers" or "protectors" when challenged by pathogens, injurious stimuli, or nanoparticulates (8-10). If excessively and chronically activated, microglia exert deleterious effects in the central nervous system (CNS) by secreting proinflammatory cytokines and interfering with synaptic integrity and functions (11, 12). Microglia exhibit at least four different functions: surveillance, phagocytosis, cytotoxicity, and neuroprotection. Depending on the nature and structure of the challenger, as well as the intensity, duration, and location of the challenge, activated microglia can take on a protective or destructive role (13). Signals from healthy and damaged neurons, astrocytes, and factors from the periphery also modulate the phenotype of activated microglia (14-16). Neuroprotection is achieved through different modes of their action, e.g., (i) synaptic stripping in development and motoneuron regeneration (5), (ii) promotion of neurogenesis in the injured CNS $(17,18)$, (iii) phagocytosis of misfolded proteins and damaged organelles $(19,20)$, and (iv) production of anti-inflammatory mediators, such as interleukin-4, interleukin-10, and transforming growth factor beta $(15,21-24)$. Cytokines, chemokines, neurotrophins, reactive oxygen species, and glutamate are endogenous signal molecules exchanged between neurons and glia cells (25-28) that can be modulated by 
pharmacological agents, but the access of these agents to the CNS may be limited by the blood-brain barrier $(29,30)$. More recently, it was shown that the microbiome can affect the integrity and function of the blood-brain barrier, as well as the maturation and phenotype of microglia (31-34). The emergence of drug nanocarriers and nanotechnological probes has facilitated the entry of therapeutics into the brain, but some of them exerted immunogenicity. The present review will focus on key neural factors and pharmacological targets in neuroinflammation, and discuss the potential of alimentary and nanotechnological agents in modulating immune processes in the brain. The merits and pitfalls of in vitro and in vivo models of neuroinflammation will be summarized, and the use of intravital imaging modalities to investigate neuroinflammation will be reviewed.

\section{MODULATORS OF NEUROINFLAMMATION}

\section{Alimentary and Environmental Neuroimmunomodulators}

Numerous genetic, environmental, and alimentary components can modulate neuroinflammation (35-37). For example, polluted urban air contains toxins, droplets, and particulates that are inhaled and travel though the blood stream, olfactory, and lymphatic systems to the brain, where they have been implicated in diseases of the CNS (37). Our daily diet can also affect neural cells, thereby altering their functions $(38,39)$. Rats fed high-fat diets were shown to have increased pro-inflammatory cytokines, such as tumor necrosis factor alpha (TNF- $\alpha$ ), interleukin-6 (IL-6), and interleukin-1 beta (IL-1 $\beta$ ), in the hypothalamus, compared to controls fed regular chow (40). The arcuate nucleus in the mediobasal hypothalamus is particularly sensitive to metabolic factors from the periphery, as it is located near the median eminence, a circumventricular organ unprotected by the blood-brain barrier (41). The activation of microglia in the arcuate nucleus of animals on high-fat diets, thus, demonstrates the direct impact of nutrition on neuroinflammation. Dietary components have also been used for therapeutic purposes as neuroprotective agents. For instance, vitamins E, C, and B have been shown to reduce oxidative stress in the brain $(42,43)$. The ketogenic diet is an established treatment for childhood epilepsy (44-46). It is thought that the increase in circulating polyunsaturated fatty acids can modulate ion channels, and that inflammation is altered by increasing circulating beta-hydroxybutyrate and activating hydroxy-carboxylic acid receptor 2 in immune cells (47-49). Ketogenic diets have since been proposed in neurological conditions, such as Alzheimer's disease and brain malignancies, but further clinical studies are required to confirm these findings and explain the beneficial effects at the molecular level (50-53). The polyunsaturated fatty acid docosahexaenoic acid (DHA) is a major component of neuronal cell membranes that is metabolized into resolvins and protectins, two families of neuroprotective lipid-derived mediators (54-56). Dietary DHA was shown to attenuate ischemic brain injury and pro-inflammatory markers in animal models (57-59). We have investigated the direct effects of DHA on synaptic integrity and indirect effects via microglia in the hippocampal CA1 region. Our studies have shown that DHA exerts neuroprotective effects in organotypic hippocampal tissue slices by preventing post synaptic spine deterioration (59). We also showed that DHA in microglia attenuates LPS-induced inflammation through the remodeling of lipid bodies and associated organelles (60). Furthermore, Bailey et al. provided evidence for the antioxidant role of lipid bodies in glia cells and neural stem cells $(61,62)$.

In addition to polyunsaturated fatty acids, such as DHA, numerous endogenous and exogenous fatty acids with different degree of saturation and chain lengths have been investigated in models of physiological and pathological conditions. The gut microbiota is an important source of small chain fatty acids (SCFA). Its population is heavily influenced by diet, and in turn, it modulates both the intestinal environment and overall human health (63-65). Once absorbed, SCFA directly impact on energy homeostasis in the liver, muscles, and adipose tissues, thereby affecting obesity and insulin resistance (66). SCFA can also affect the CNS by modulating neuroendocrine and cognitive responses, particularly when changes in the gut microbiome lead to increased intestinal permeability $(34,67,68)$. Emerging research on the gut-brain axis has shown that there is a tight link between the gut microbiota and the function of neural cells. The gut microbiota are necessary for the early and normal development of the brain, and contribute in programing the hypothalamic-pituitary-adrenal axis (69). In germ-free mice, microglia were found to have an immature phenotype, resulting in altered immune responses (31). Chronic enteric infections and antibiotics can also drastically modify the gut microbiome, resulting in neuropsychological symptoms $(34,70)$. The term "psychobiotics" has since been coined, referring to probiotics benefiting psychiatric illness, but further clinical studies are required to demonstrate the therapeutic benefits (71). While the composition and function of the gut microbiota can be affected by alimentary components, they can also be influenced by food contaminants, including nanoparticulate matter.

\section{Nanotechnological Immunomodulators}

Mammals have been exposed to airborne, waterborne, foodborne, and other nanomaterials in the environment for millennia and have developed mechanisms to deal with them $(72,73)$. Nevertheless, the explosion of nanoparticles in electronics, medical devices, paints, clothing, and cosmetics raised the awareness of the nanostructured materials in everyday life, requiring careful monitoring and analysis of the level and type of nanoparticles in soil, water, and air (74). In recent years, many nanomaterials have been designed for the development of diagnostics, delivery of therapeutic agents, and implants for the replacement of missing or impaired organ parts (e.g., joints, heart) (75-78). Some of these materials are well tolerated and efficiently eliminated, but others induce immune reactions and are toxic. Nanostructured materials are mainly recognized by cells of the immune system, primarily the mononuclear phagocytic system (MPS) (79). For example, internalized carbon nanotubes can be partly degraded in macrophages and the extent of biodegradation may be a major determinant in the severity of the associated inflammatory responses (80). Nanomaterial accumulation in macrophages 
within clearance organs (e.g., liver, kidneys, and spleen) can initiate both acute and chronic inflammation $(81,82)$. Although nanomaterials can cause toxic responses in these organs, technological manipulations of their morphologies, surfaces, sizes, charges, and porosities can minimize adverse effects (83-85). The structure-activity relationship of several classes of nanoparticles and outcome measures in immune and non-immune cells has been previously discussed $(86,87)$.

Our laboratory is particularly interested in investigating the effects of nanomaterials on microglia because of increasing evidence that (1) microglia are the major "consumers" of nanoparticles in the CNS $(10,88,89)$, (2) microglia and macrophages contribute to the maintenance and progression of glioblastoma, one of the most complex and deadly brain tumors (90), and (3) there is a structural and functional link between the CNS and lymphatic vessels (91). The discovery that lymphatic vessels lining dural sinuses are gateways between the systemic lymphatic system and the brain has recently re-defined our understanding of the immune system of the brain and is seminal in investigating neuroinflammatory and neurodegenerative disorders associated with impairments of the immune system. The majority of the studies showing either positive or negative effects of nanomaterials on the immune system focused on peripheral macrophages. This is understandable considering that most foreign materials are taken up by these cells. However, brain cancers, such as gliomas, are infiltrated mainly by the brain macrophages, the microglia. In fact, the proportion of microglia in low-grade gliomas can exceed $(>35 \%)$ the normal microglia contribution (10-15\%) in non-neoplastic brains. The majority of non-neoplastic cells in gliomas are tumorassociated macrophages (TAM) either originating from the periphery or intrinsic to the brain $(90,92)$. These cells form the microenvironment of the brain tumor and play a major role in the maintenance and progression of the cancer cells. They can contribute to cancer survival, invasiveness, and proliferation. Although the mechanisms underlying microglia stimulation of low- and high-grade gliomas are not fully understood, the existence of a unique tumor microenvironment resulting from the infiltration of central and peripheral macrophages provides an opportunity to establish more effective chemotherapeutic interventions (93). Achieving this goal is not simple because of the considerable diversity and plasticity of macrophages and microglia. The common classification of M1 polarization, deemed pro-inflammatory, and M2, designating alternatively activated macrophages (with subclasses M2a, M2b, and M2c), seems inadequate for TAM. RNA microarray analyses indicated that about 1000 transcripts were found to be differently expressed in glioblastoma-associated microglia and macrophages relative to control microglia. The expression patterns only partially $(<50 \%)$ overlapped with reported gene signatures for M1 and M2 macrophages (94). Therapeutic interventions targeting glioblastoma cells alone usually failed because of the contribution of the complex environment made of surrounding cells and brain tumor stem cells $(95,96)$. The problem is that macrophages and microglia secrete growth- and invasion-promoting factors, whereas brain tumor stem cells residing in perivascular niches often give raise to the resistance to radiation and chemotherapy
(97-100). By contrast, some data suggest that the ketogenic diet combined with standard cancer treatment could increase the sensitivity of cancer cells toward therapies due to their reliance on glycolytic metabolism (101). Such a diet could also decrease inflammation caused by infiltrating macrophages and microglia. Although the results are encouraging, additional clinical trials are required to confirm the previous findings, suggesting the beneficial effects of the ketogenic diet (102). Immunomodulation of the glioma microenvironment by nanoparticles is also an attractive therapeutic avenue to reduce tumor invasiveness and growth. Data from preclinical and clinical studies are encouraging despite limitations and hurdles, which need to be overcome before this strategy becomes more widely applied (103-105).

In inflammation, immunomodulation using nanoparticles could provide suitable alternatives to standard treatment strategies because of the versatility of particle surface modifications, compositions, and charges. Particles with a negative surface charge can bind to monocytes, marking them for sequestration by the spleen and preventing their migration and participation at the inflammation site (65). Interesting examples of polyanions with anti-inflammatory effects are dendritic polyglycerol sulfates (dPGS) (106-108). Studies with dPGS suggest that they are effective anti-inflammatory agents per se with strong inhibitory effects on inflammation-induced degenerative changes in microglia and the ability to rescue dendritic spine morphology (108). Their L-selectin binding in the low nanomolar range, limited impact on blood coagulation, and minor activation of the complement system render them attractive anti-inflammatory agents (106). A simplified molecular mechanism of dPGS binding to selectins and their intracellular location in microglia is illustrated (Figure 1).

Mechanisms for nanoparticle-induced tolerance and reduction of inflammation severity have been previously reviewed in Ref. (109). Although there are still numerous unanswered questions related to the mechanisms of nanoparticle-immune system interactions, it is anticipated that in the next decade, clinical studies will show if negatively charged biodegradable nanoparticles (e.g., polylactic-polyglycolic acid) will reduce severe inflammations in myocardial infarction and acute encephalitis syndrome. If these and similar studies show a positive outcome, nanoparticle-based therapies could become a valuable addition to existing therapies targeting the immune system (110). However, a series of safety testing and validation has to be performed in preclinical and clinical investigations. A tiered approach for assessing nanoparticle compatibility with the immune system in vitro during the early phase of preclinical development, strategies for designing early phase preclinical immunotoxicity screening, and challenges associated with these investigations have been reviewed in Ref. (86). Despite disappointments due to the lack of standards and standardized procedures, limited understanding of underlying mechanisms involved in nanoparticle-immune cell interactions, inadequate nanoparticle characterization and incomplete knowledge about plasma proteins and their interactions with nanoparticle surfaces under physiological and pathological conditions, results obtained so far have provided a baseline for investigations to harness biocompatible and safe nanomaterials for immunomodulation. 

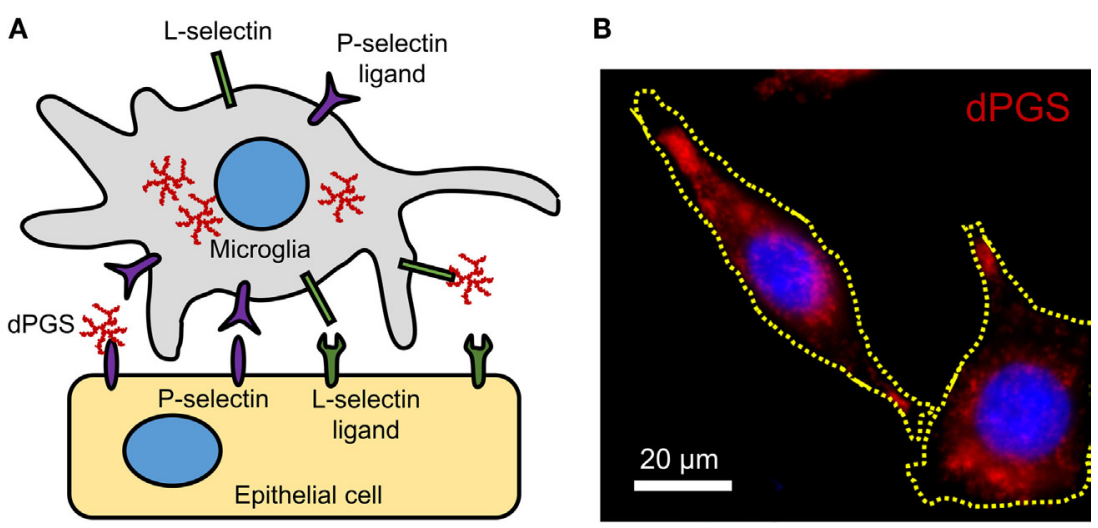

FIGURE 1 | (A) Molecular mechanism of dPGS binding to L-selectins and P-selectin ligands. (B) Fluorescence micrograph of fluorescently labeled dPGS (red) in microglia. Nuclei are labeled with Hoechst 33342 (blue).

\section{MODELS OF NEUROINFLAMMATION}

\section{In Vitro Models}

Neuroinflammation involves complex intercellular communication between different neural cell types organized into intricate networks. Thus, suitable primary neural cells in 3D cultures (prepared either from dissociated cells or organotypic slices) are preferable to cell line models grown in 2D (Figure 2). However, both types of in vitro models have important limitations (Table 1). Phenotypic traits of primary cells are often lost following in vitro culture, particularly in monolayer and monocultures. Microglia are ramified in the healthy brain and in astrocyte co-cultures, but in the absence of astrocytic support, they take on various morphologies (e.g., amoeboid, spindle, and rod like) (111). Astrocyte-conditioned media are only partly effective in maintaining the ramified morphology of microglia, because astrocytes provide not only soluble (e.g., granulocyte macrophage colonystimulating factor and colony-stimulating factor 1) but also nondiffusible factors. An astrocyte feeder layer is commonly used to support microglia and neuronal cultures alike $(112,113)$. This can be achieved using a two-chamber culture system comprising an enriched microglia culture separated from an enriched astrocyte culture by an inset with a porous membrane.

Immortalized microglia cell lines were initially established from rodents in the 1980s, and the first human cell line was reported in 1995 (114). N9 and BV2 are among the oldest and best-described murine microglia cell lines, while CHME and HMO6 are the main human microglia cell lines. Recently, another immortalized microglia cell line was generated from the adult murine brain (131). Beside the practical advantages of an established cell line, immortalized microglia provide a relatively homogeneous cell population that retains the phagocytic and secretory abilities of their primary counterparts. However, surface markers vary from cell line to cell line, and as with any continuous cell culture, phenotypic traits may change as cells differentiate over time (114). The systematic analysis of primary mouse and human microglia genes and microRNAs identified a unique molecular signature that was distinct from peripheral immune cells and immortalized microglia cell lines. This striking difference between primary and immortalized cells indicates that continuous cell lines are not always suitable to answer some questions, such as the role of surface markers highly expressed in human or mouse microglia [e.g., purinergic receptor P2Y, G-protein coupled, 12 (P2ry12) in human, and Fc receptor-like S (FCRLS) in mouse microglia] $(132,133)$.

Brain slices are 3D, ex vivo models with partial brain architecture and synaptic circuitries. These models are used to investigate intercellular communication between neural cells under "physiological" and pathological conditions. Organotypic brain cultures are usually prepared from postnatal animals (days 3-9), and slices are maintained in culture until the maturation of the synaptic networks. Although the structural development of organotypic brain slices has been found to be largely comparable to that of age-matched animals, it has been reported that these ex vivo cultures had increased dendrite numbers and glutamatergic synaptic currents resulting from the rewiring of axons damaged during the initial slice preparation (120). Nevertheless, the preservation of tissue structure and the presence of microglia in organotypic brain slices are major advantages in the study of neuroinflammation. Acute brain slices are similar to organotypic brain cultures. They can be harvested from animals of any age, and experiments are typically completed within hours. However, the biomechanical stress caused by tissue slicing, presence of damaged cells, and release of soluble factors from these cells must be considered when interpreting results from such preparations (134).

Inflammation in neural cells can be induced using pathogenderived ligands, pro-inflammatory cytokines, and injurious stimuli. Among the most common pro-inflammatory stimuli is lipopolysaccharide (LPS), an endotoxin from Gram-negative bacteria, which binds to toll-like receptor 4 (TLR4) on microglia, astrocytes, oligodendrocytes, and neurons $(14,135)$. The production of cytokines (e.g., interleukin-1 beta, interleukin-6, interleukin-18, interleukin-33) by microglia in response to LPS is mediated by the inflammasome, a multiprotein complex typically composed of pro-caspase-1, the adaptor molecule apoptosisassociated speck-like protein containing a caspase recruitment 


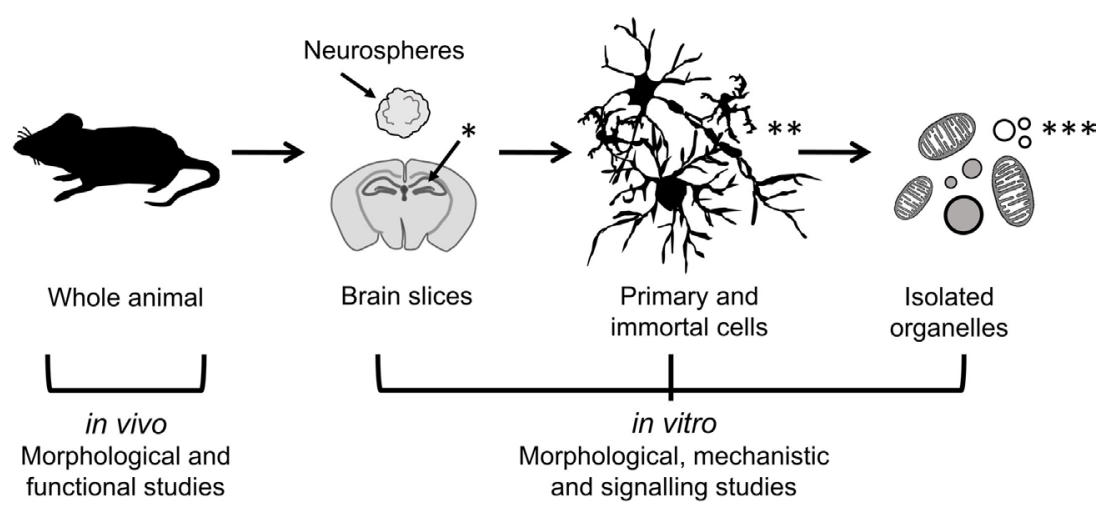

FIGURE 2 | Models of different complexity used to study the effects of immunomodulators in neural cells. In vivo models of neuroinflammation are most suitable for morphological and functional studies, while in vitro models of neural cells in 2D (primary and immortal dissociated cells) and 3D (neurospheres and brain slice cultures) are useful for morphological, mechanistic, and signaling studies. Isolated organelles can be used to investigate mechanisms of inflammation at the subcellular level. [ ${ }^{*}$ Hippocampus (hippos = horse; campos = sea monster); ${ }^{* *}$ neurons, microglia, astrocytes; ${ }^{* \star *}$ organelles: mitochondria, lipid droplets, lysosomes, nucleoli.]

domain (ASC) and nucleotide-binding oligomerization domain, leucine-rich repeat-containing receptor (NLR) family proteins (Figure 3) (136). Different types of inflammasomes can assemble depending on the nature and intensity of the stimulus, and many members of the NLR family can facilitate the assembly (e.g., NLRP1, NLRP7, and NLRP12). In particular, the NLR family, pyrin domain-containing 3 (NLRP3) inflammasome is common in neuroinflammation-associated disorders, and can be regulated by a wide variety of factors, such as pathogen-associated molecular patterns, damage-associated molecular patterns, COX-2 activity, and damaged mitochondria (137-139). In Alzheimer's disease, traumatic brain injuries (TBI), and MS, the NLRP3 inflammasome was found to exacerbate inflammatory responses and damage mediated by microglia (140-143). Notably, hyperactivation of microglia characterized by inflammasome activation and cytokine release can lead to the programed cell death pyroptosis in neural cells (144-146). Pro-inflammatory cytokines are major inducers of immune activation, both in the peripheral and central immune systems. These include, among others, TNF- $\alpha$, IFN $\gamma$, IL-1 $\beta$, and IL- $6(26,147,148)$. Modulation of IL- 6 classical and trans-signaling has been exploited for therapeutic interventions in several preclinical and clinical trials $(149,150)$. The evolutionary conserved glycoprotein 130 (gp130) system inspired the development of sgp130Fc, an effective pharmacological tool to distinguish classical from trans-signaling. The results from phase III studies with sgp130Fc are awaited - it is anticipated that blockade of trans-signaling will prove to be superior to the global blockade of IL-6 signaling by the neutralizing antibody tocilizumab. Recent studies showed that the small molecule LMT-28 can also block trans-signaling of IL-6 (151). LMT-28 is stable, simple to synthesize, and functions by binding directly to gp 130 . Clinical data for its effectiveness in neurological disorders are not yet available. Anti-inflammatory cytokines, such as interleukin-4 and -10 , can dampen the effects of pro-inflammatory stimuli. The production of these secreted factors can be monitored using enzyme-linked immunosorbent assays (ELISA). Inflammation induced by ischemic and TBI is difficult to replicate in vitro, but some morphological and biochemical changes can be assessed in simplified models. For instance, oxygen and glucose deprivation (OGD) is often used to mimic brain ischemia and induce the activation of toll-like receptors 2 and 4 in primary cortical neurons (135). Transection, compression, hydrostatic pressure, and stretch injuries are other examples of brain "injuries in the dish" (134).

\section{In Vivo Models}

A great number of animal models of neuroinflammation are available today, many of which are disease specific (see examples in Table 1). Although transgenic animals are popular to examine the effects of gene knock-in and knock-out, wild-type animals remain necessary to understand the fundamental pathophysiology of neuroinflammation. LPS can be injected either systemically or intracranially. Circulating LPS rapidly causes an inflammatory response in the brain, first at the circumventricular organs, then across the CNS (152). Although the choice of LPS serotype has little impact on TLR4 stimulation, it can significantly affect in vivo studies involving the adaptive immune system. The degree of purity of the LPS is also an important factor, as products of lesser quality can contain other pathogen-associated molecules that will alter the potency of the LPS and the magnitude of the inflammatory response. Systemic injection is often administered intraperitoneally, intravenously, or by stereotaxic administration directly into the brain parenchyma. The stereotaxic apparatus holds the head of the animal in place and a stereotaxic atlas is used to determine the coordinates for the site at which a small hole in the skull should be drilled to access a specific site in the brain (153). Until recently, innate recognition of LPS was limited to its membrane receptor TLR4/MD-2-stimulated cytokine transcription. Therapeutic intervention by Eritoran has achieved very moderate success in sepsis (154). This could be in part because of the existence of non-canonical LPS signaling induced by cytosolic LPS. This non-canonical signaling via intracellular 
TABLE 1 | Models of immunomodulation: from in vitro to in vivo models.

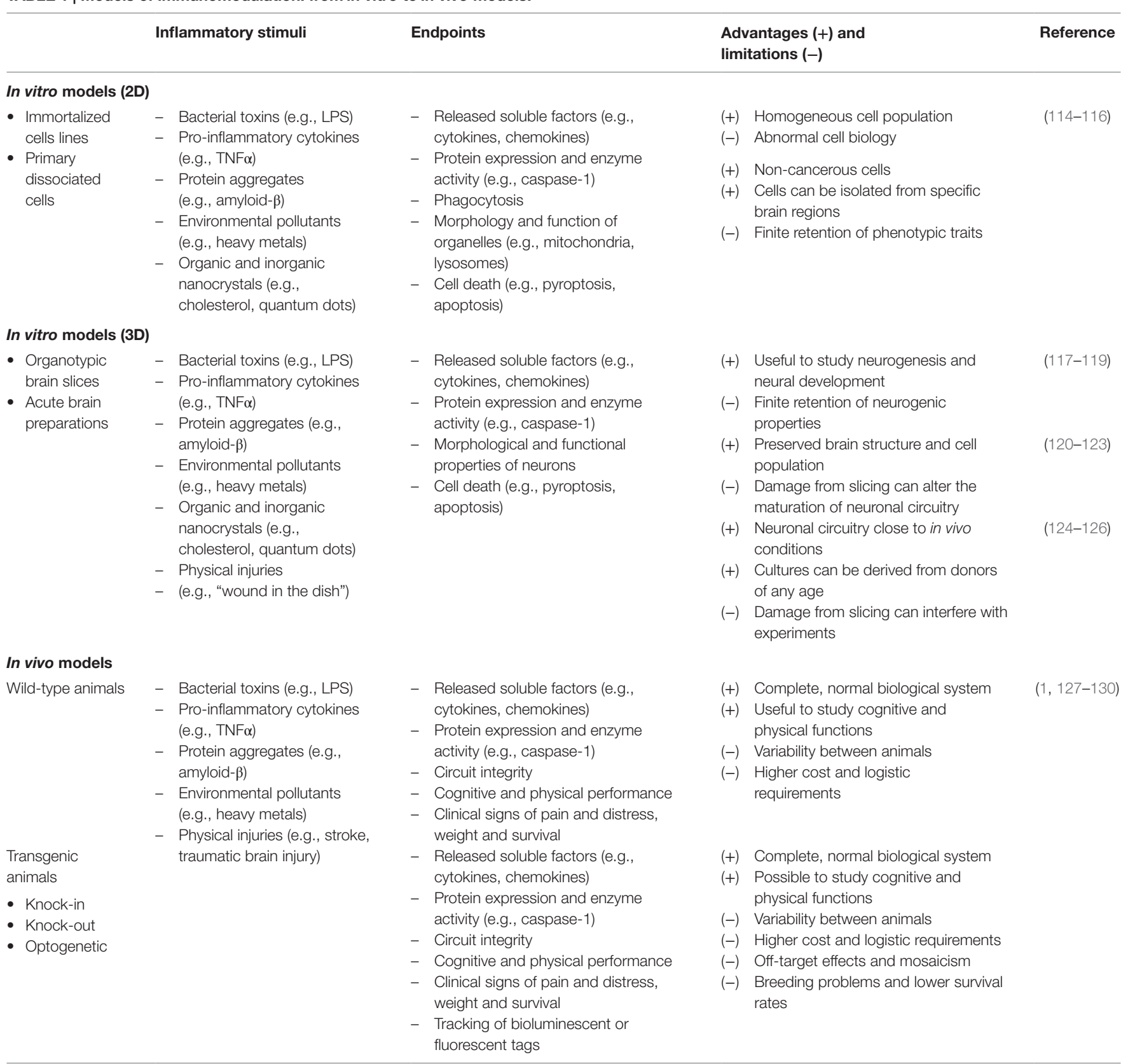

LPS activates pro-inflammatory caspases - caspase-11 in mice and caspase-4/5 in humans - and does not depend on TLR4 (155-157). LPS binding to caspases induces their oligomerization, which is a prerequisite for caspase activation. A simplified model of canonical and non-canonical signaling by LPS is illustrated (Figure 4). Resulting CNS complications, such as encephalopathy, are mainly mediated by neuroinflammation and oxidative stress (158). Aside from LPS administration, inflammation can be induced more globally by bacterial infections. A standard method to induce polymicrobial sepsis is cecal ligation (159). It is easily performed, and the severity of the disease can be controlled to a certain extent (160). However, there is a high mortality rate, and variable outcomes have been observed between animals and laboratories (161).

Inflammatory processes in transgenic models of neuroinflammation often result indirectly from the expression of a diseasespecific mutant gene, and most models were developed for the study of neurodegenerative diseases. The APP/PS1 mouse model, for instance, is used in the study of Alzheimer's disease. These mice express a chimeric amyloid precursor protein and a mutant human presenilin-1, causing the accumulation of amyloid-beta plaques by the age of 6 months, extensive neuroinflammation and, later on, memory impairment (162). By contrast, it was recently suggested that the amyloid beta peptide can protect 


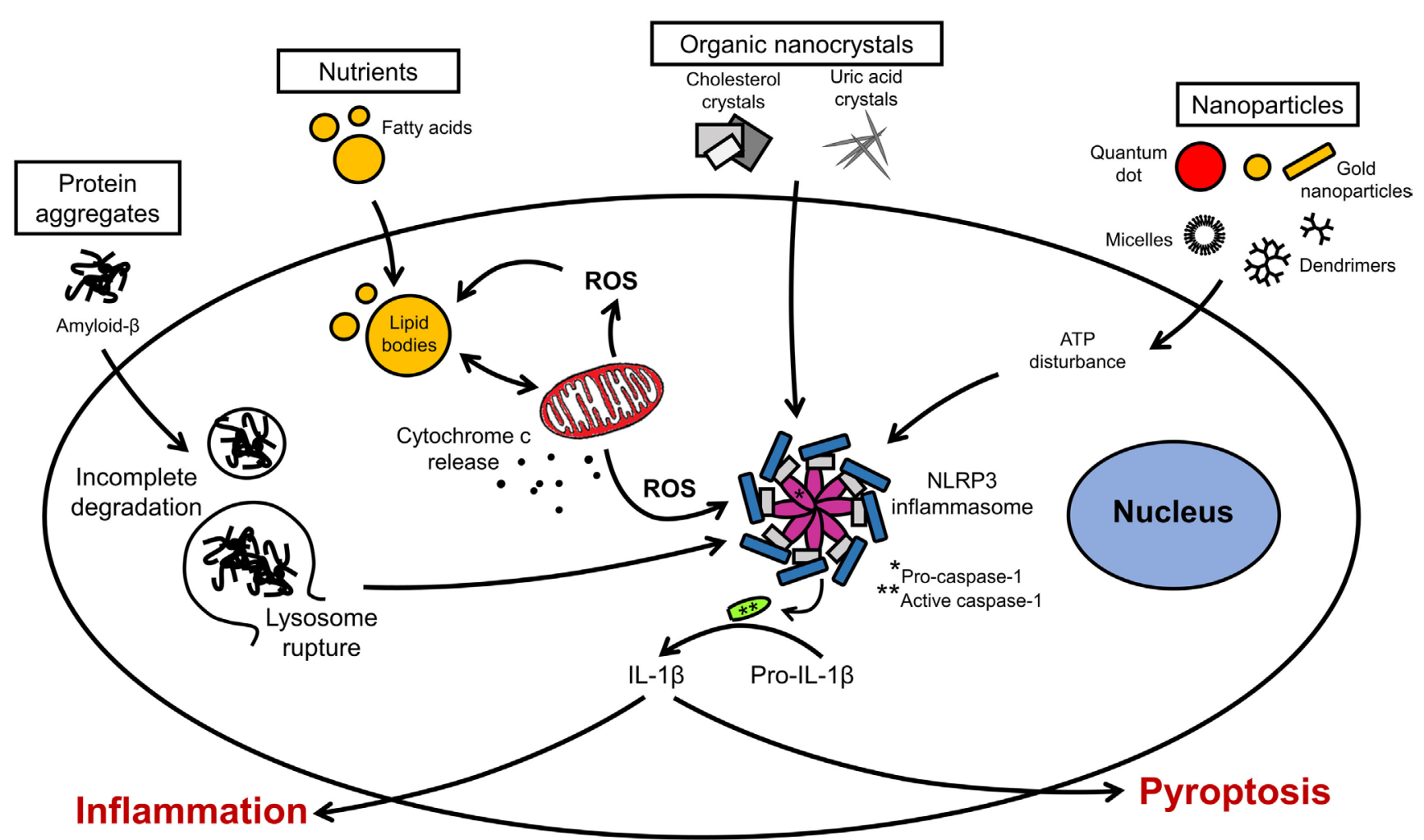

FIGURE 3 | Organellar remodeling in inflammation. Multiple pro-inflammatory stimuli can disrupt redox homeostasis in microglia. Mitochondria are the major source of reactive oxygen species (ROS). Excessive ROS induces the formation of lipid bodies and impairs their communication with intracellular organelles. Several signal transduction pathways implicated in inflammation converge on the inflammasome. Inflammasome activation leads to the caspase activation and cytokine release. Modulation of these pathways can lead to resolution of inflammation or exacerbation with pyroptotic cell death.

against microbial infection in a mouse model of Alzheimer's disease (163). This is an intriguing proposition, raising the possibility that amyloid beta may play a protective role in innate immunity through its binding to microbial cell walls via heparinbinding domains. In the adeno-associated virus-alpha-synuclein mouse model of Parkinson's disease, the animal expresses alphasynuclein under the control of a viral promoter. This results in the loss of dopaminergic neurons, as well as the activation of microglia (164). For the study of amyotrophic lateral sclerosis, transgenic mice expressing a mutant superoxide dismutase 1 gene were observed to show astrocyte and microglia activation, leading to motoneuron degeneration and muscle atrophy $(165,166)$. Transgenic mouse models used to investigate neuroinflammation can provide valuable information on morphological, biochemical, and functional changes in neural cells, but they have limitations that must be considered in the context of human pathology (1). Other knock-out and knock-in animals have also been employed to study the role of key mediators of neuroinflammation. Caspase-1 knock-out mice, for example, seemed more resistant to ischemia-induced neural cell death than wild-type animals (167). More recently, the clustered regularly interspaced short palindromic repeats (CRISPR) and CRISPR-associated protein- 9 (Cas9) gene editing technique has generated considerable excitement, as it was successful in targeting single or multiple genes in the mouse brain (168). The technique allows the generation of mutant animals with ease and efficiency compared to the traditional transfection of mouse embryonic stem cells. However, emerging problems include off-site effects and mosaicism (169).

\section{INTRAVITAL IMAGING OF NEUROINFLAMMATION}

A great variety of reporters and probes are currently available to investigate neuroinflammation at the cellular level (170-173). Cellular events of interest include the migration and phagocytic activity of microglia, the infiltration of peripheral immune cells, as well as the production of secreted factors, metabolism, and viability of neural cells. Intravital imaging is useful to study the pathophysiology of neuroinflammation in a non-invasive manner, but an important limitation is the scattering and absorbance of light entering biological tissues. The availability of strong reporters and powerful imaging modalities have allowed for better detection and facilitated the generation of quantitative data from investigated signals while minimizing autofluorescence. The natural fluorescence of different tissues can mask signals from fluorescent probes. Lipofuscin, which can be excited anywhere in the range of 360-647 nm, is commonly found in neurons and glia cells, and increases with animal age. The imaging of green fluorescent protein, one of the most common and popular fluorescent labels, can also be hindered by a subset of green autofluorescent cells 


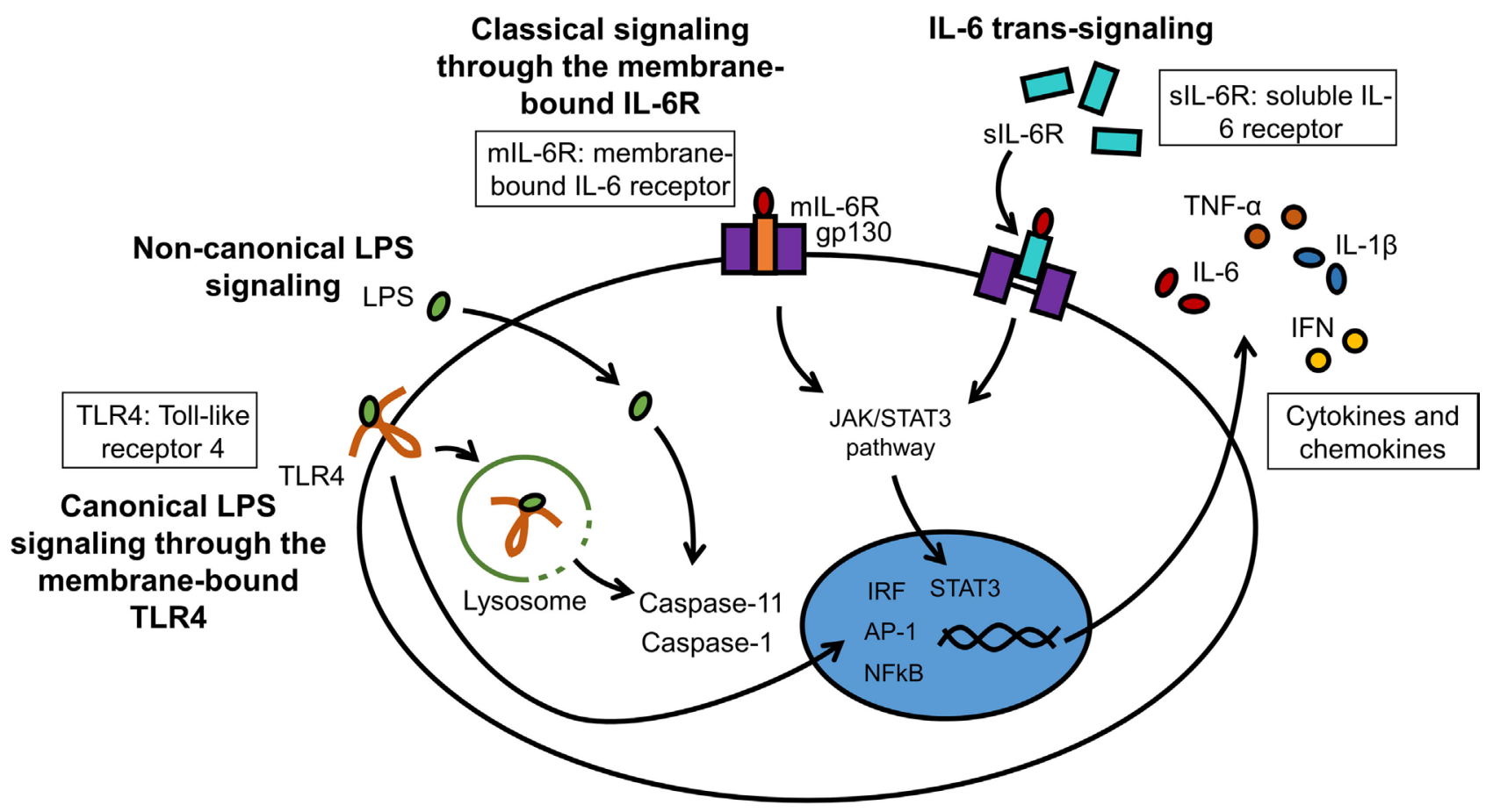

FIGURE 4 | LPS and IL-6 signaling in microglia. LPS can interact with membrane-bound TLR4 (canonical signaling) or can enter the cytosol independently from TLR4 (non-canonical signaling). The major cytosolic receptors for LPS are pro-inflammatory caspases. IL-6 binds either to the membrane receptor IL-6R (mIL-6R; classical signaling) or to the soluble IL-6 receptor (SIL-6R; trans-signaling). These receptor complexes subsequently bind to gp130 to initiate intracellular signaling cascades.

in the rat cortex and hippocampus (174). In tissue sections, the risk of false positives can be reduced by using autofluorescence quenchers, such as copper sulfate (175). The choice of fluorophores emitting in the near-infrared spectrum can be made to avoid this issue. Imaging of structural and functional changes in the living brain can be performed using open-skull preparations, where a small window in the skull is protected by a glass coverslip. Following the implantation of the cranial window, a recovery time is necessary to avoid inflammation caused by the surgery $(176,177)$. However, long-term imaging using the open-skull technique can be obscured by bone re-growth and the thickening of the meninges (178). Imaging of the cortex using the thinnedskull cranial window technique is useful when longer intervals are needed in between imaging sessions. However, repeated imaging requires the re-thinning of the skull, which has to be carefully monitored to avoid cortical trauma and inflammation $(179,180)$. For both imaging techniques, two-photon microscopy in the near infrared region is suitable to avoid photobleaching and photodamage.

Transgenic animals expressing luciferase in glia cells have been employed to track and image processes in neuroinflammation at the cellular level (181-183). Our studies have shown marked activation of microglia, pro-inflammatory caspases, and astrocytes by nanocrystals (184-186). Data from these studies showed that stable nanocrystals injected directly into the parenchyma of mice induced transient astrocyte activation, suggesting that only nanocrystals adequately coated with polyethylene glycol (PEG) are suitable nanotechnological tools. Glia cells were also activated by gold nanoparticles, depending on the nanoparticles' morphology (10). Activation of glia cells is often accompanied by the activation of inflammatory caspases and caspases implicated in apoptosis (187). Nanosensors for caspases have been developed, and examples of constructs for these sensors are illustrated in Figure 5 (170, 188).

A whole palette of fluorescent proteins, mostly mutant derivatives of the jellyfish's green fluorescent protein, have also been employed to "illuminate" the brain. The use of cell-typespecific fluorescent labels allowed to map brain structures and to distinguish different cell populations with greater accuracy. High-resolution pictures have been recorded in recent years, and unprecedented 3D images and videos have been produced from fluorescently labeled brain tissues $(189,190)$. Although the quality of these imaging techniques remains variable and is dependent on the success of the genetic probes and the available imaging modalities, these techniques have been instrumental in understanding structural and functional aspects of the CNS - including glia-neuron interactions. Optogenetics have also been used to study light-responsive channels and other proteins in neural cells (191-193). For instance, the selective expression of channelrhodopsin-2, a light-responsive membrane channel, has been employed to study calcium signaling in astrocytes in vitro and in vivo (194). Optogenetic tools could, thus, be used to reveal the contribution of microglia in neuroinflammatory processes (195). Although optogenetics has generated valuable information on macromolecules in cells, this approach cannot be applied to investigate small molecules, such as phospholipids. More 
A

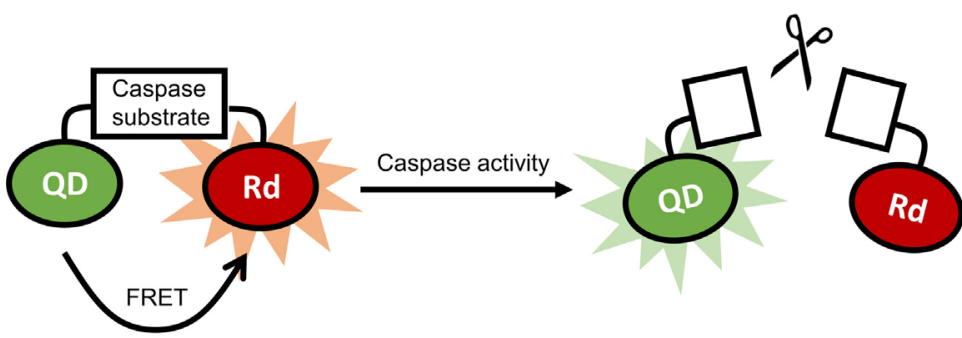

B
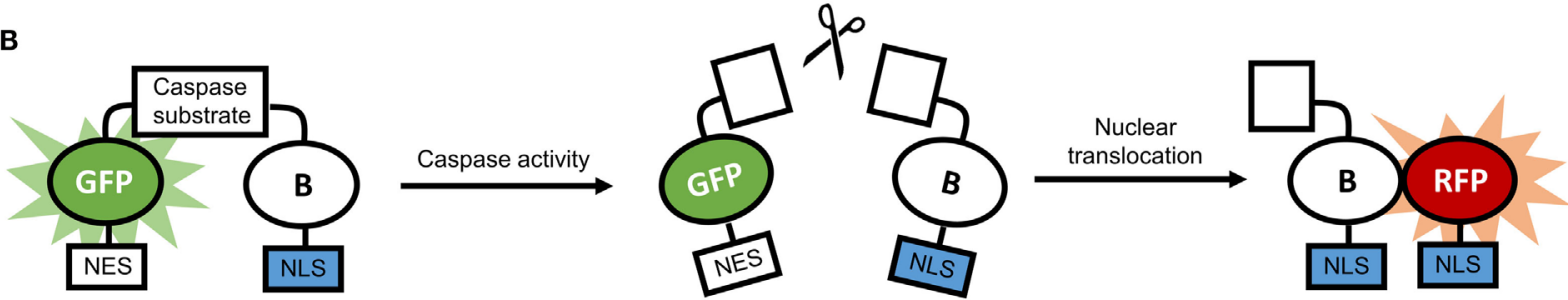

FIGURE 5 | (A) Schematic representation of a quantum dot-based sensor for caspase activity. In the absence of caspase activity, there is fluorescence resonance energy transfer (FRET) between the quantum dot (QD) and the rhodamine molecule (Rd), and the fluorescence of the QD is quenched. In the presence of caspase activity, FRET is disrupted, and the QD is fluorescent. (B) Schematic representation of a ratiometric biosensor for caspase activity. In the absence of caspase activity, the dimerization-dependent green fluorescent protein (GFP) is dimerized with the partner protein B and is retained in the cytoplasm through a nuclear exclusion signal (NES). In the presence of caspase activity, the dimerization is disrupted, and B translocated to the nucleus using a nuclear localization signal (NLS), and associates with the dimerization-dependent red fluorescent protein (RFP). As a result, green fluorescence in the cytoplasm fades, and red fluorescence in the nucleus increases.

recently, the approach of optolipidomics was used to study the processing of mitochondria-specific cardiolipins in apoptosis (196). Mitochondrial functions are often impaired in inflammatory processes, and the combination of optogenetics and optolipidomics could provide complementary information on underlying intricacies in neuroinflammation.

\section{CONCLUSION}

Neuroinflammation is considered a significant contributor in many neurodegenerative diseases. Microglia are the immune cells of the CNS, and are modulated by numerous factors, including alimentary products and the gut microbiome. Nanoparticulates have emerged as a new group of "xenobiotics" that must be thoroughly characterized prior to investigating their immunomodulatory effects in the CNS and elsewhere. Nanotechnology offers a wide selection of shape- and size-tunable probes, ranging from quantum dots to fluorescently labeled polymeric constructs (163). Nanoprobes can be brighter and more stable than genetic probes, and designed to "activate" in response to a particular stimuli, such as light or acidic $\mathrm{pH}$. However, nanotechnological probes are often large and cannot reach desirable intracellular locations. In addition, these probes are complex and relatively little is known about their stability in vivo, as well as their pharmacokinetics and pharmacodynamics $(186,187)$. It is well established that the biological identity of a nanoparticle is distinct from its well-defined chemical identity. Serum protein binding, sensitivity to $\mathrm{pH}$, and clearance rates are all factors affecting the immunogenicity and fate of a nanoparticle in vivo $(146,147)$. On the other hand, nanoparticle-induced immune responses can be exploited for improving vaccine efficiency and boost the immune system in pathologies with weakened immune responsiveness (197-199). Diverse fluorescent nanostructures can provide tools for the tracking and imaging of complex networks in different cell types in a spatio-temporal manner. The combined use of nanotechnological tools and advanced intravital imaging techniques can, thus, provide unprecedented insight into the mechanisms of neuroinflammation. Exciting data related to brain abnormalities implicating glial cells come from gene editing techniques, such as CRISPR/Cas9 (168). Animal studies exploiting these approaches in mice models of neurodegenerative diseases will help to reveal intricacies in neural circuitries under physiological conditions and mechanisms involved in multifactorial diseases associated with neuroinflammation.

\section{AUTHOR CONTRIBUTIONS}

DM outlined, co-wrote, and revised the manuscript. IZ drafted and finalized the figures and table, and co-authored the text. Both authors read and approved of the final version of the manuscript.

\section{ACKNOWLEDGMENTS}

The authors thank Mr. Jeff Ji for reading the manuscript. This work was supported by grants from the Natural Sciences and Engineering Council of Canada (RGPIN-2015-04994) and the Canadian Institutes of Health Research (119425). 


\section{REFERENCES}

1. Heneka MT, Kummer MP, Latz E. Innate immune activation in neurodegenerative disease. Nat Rev Immunol (2014) 14:463-77. doi:10.1038/ nri3705

2. Hunot S, Hirsch EC. Neuroinflammatory processes in Parkinson's disease. Ann Neurol (2003) 53(Suppl 3):S49-58. doi:10.1002/ana.10481

3. Nolan YM, Sullivan AM, Toulouse A. Parkinson's disease in the nuclear age of neuroinflammation. Trends Mol Med (2013) 19:187-96. doi:10.1016/j. molmed.2012.12.003

4. Whalley K. Neuroinflammation: transport disruption in multiple sclerosis. Nat Rev Neurosci (2015) 16:2-2. doi:10.1038/nrn3892

5. Kettenmann H, Kirchhoff F, Verkhratsky A. Microglia: new roles for the synaptic stripper. Neuron (2013) 77:10-8. doi:10.1016/j.neuron.2012. 12.023

6. Perry VH, Nicoll JAR, Holmes C. Microglia in neurodegenerative disease. Nat Rev Neurol (2010) 6:193-201. doi:10.1038/nrneurol.2010.17

7. Chen Z, Trapp BD. Microglia and neuroprotection. J Neurochem (2016) 136(Suppl 1):10-7. doi:10.1111/jnc.13062

8. Sierra A, Beccari S, Diaz-Aparicio I, Encinas JM, Comeau S, Tremblay M-È. Surveillance, phagocytosis, and inflammation: how never-resting microglia influence adult hippocampal neurogenesis. Neural Plast (2014) 2014:610343. doi:10.1155/2014/610343

9. Kreutzberg GW. Microglia: a sensor for pathological events in the CNS. Trends Neurosci (1996) 19:312-8. doi:10.1016/0166-2236(96)10049-7

10. Hutter E, Boridy S, Labrecque S, Lalancette-Hébert M, Kriz J, Winnik FM, et al. Microglial response to gold nanoparticles. ACS Nano (2010) 4:2595-606. doi:10.1021/nn901869f

11. Block ML, Zecca L, Hong J-S. Microglia-mediated neurotoxicity: uncovering the molecular mechanisms. Nat Rev Neurosci (2007) 8:57-69. doi:10.1038/ nrn2038

12. Hanisch U-K. Microglia as a source and target of cytokines. Glia (2002) 40:140-55. doi:10.1002/glia.10161

13. Hanisch U-K, Kettenmann H. Microglia: active sensor and versatile effector cells in the normal and pathologic brain. Nat Neurosci (2007) 10:1387-94. doi:10.1038/nn1997

14. Lehnardt S. Innate immunity and neuroinflammation in the CNS: the role of microglia in Toll-like receptor-mediated neuronal injury. Glia (2010) 58:253-63. doi:10.1002/glia.20928

15. Cherry JD, Olschowka JA, O'Banion MK. Neuroinflammation and M2 microglia: the good, the bad, and the inflamed. J Neuroinflammation (2014) 11:98. doi:10.1186/1742-2094-11-98

16. Savarin C, Hinton DR, Valentin-Torres A, Chen Z, Trapp BD, Bergmann CC, et al. Astrocyte response to IFN- $\gamma$ limits IL-6-mediated microglia activation and progressive autoimmune encephalomyelitis. J Neuroinflammation (2015) 12:79. doi:10.1186/s12974-015-0293-9

17. Ernst A, Alkass K, Bernard S, Salehpour M, Perl S, Tisdale J, et al. Neurogenesis in the striatum of the adult human brain. Cell (2014) 156:1072-83. doi:10.1016/j.cell.2014.01.044

18. Nikolakopoulou AM, Dutta R, Chen Z, Miller RH, Trapp BD. Activated microglia enhance neurogenesis via trypsinogen secretion. Proc Natl Acad Sci U S A (2013) 110:8714-9. doi:10.1073/pnas.1218856110

19. Sierra A, Abiega O, Shahraz A, Neumann H. Janus-faced microglia: beneficial and detrimental consequences of microglial phagocytosis. Front Cell Neurosci (2013) 7:6. doi:10.3389/fncel.2013.00006

20. Brown GC, Neher JJ. Microglial phagocytosis of live neurons. Nat Rev Neurosci (2014) 15:209-16. doi:10.1038/nrn3710

21. Lindholm D, Castrén E, Kiefer R, Zafra F, Thoenen H. Transforming growth factor-beta 1 in the rat brain: increase after injury and inhibition of astrocyte proliferation. J Cell Biol (1992) 117:395-400. doi:10.1083/jcb. 117.2.395

22. Liu X, Liu J, Zhao S, Zhang H, Cai W, Cai M, et al. Interleukin-4 is essential for microglia/macrophage M2 polarization and long-term recovery after cerebral ischemia. Stroke (2016) 47:498-504. doi:10.1161/STROKEAHA. 115.012079

23. Park KW, Lee HG, Jin BK, Lee YB. Interleukin-10 endogenously expressed in microglia prevents lipopolysaccharide-induced neurodegeneration in the rat cerebral cortex in vivo. Exp Mol Med (2007) 39:812-9. doi:10.1038/ emm. 2007.88
24. Ledeboer A, Brevé JJ, Poole S, Tilders FJ, Van Dam AM. Interleukin-10, interleukin-4, and transforming growth factor-beta differentially regulate lipopolysaccharide-induced production of pro-inflammatory cytokines and nitric oxide in co-cultures of rat astroglial and microglial cells. Glia (2000) 30:134-42. doi:10.1002/(SICI)1098-1136(200004)30:2<134::AID-GLIA3> 3.0.CO;2-3

25. Fields RD, Stevens-Graham B. New insights into neuron-glia communication. Science (2002) 298:556-62. doi:10.1126/science.298.5593.556

26. Choi SS, Lee HJ, Lim I, Satoh J, Kim SU. Human astrocytes: secretome profiles of cytokines and chemokines. PLoS One (2014) 9:e92325. doi:10.1371/ journal.pone.0092325

27. Elkabes S, DiCicco-Bloom EM, Black IB. Brain microglia/macrophages express neurotrophins that selectively regulate microglial proliferation and function. J Neurosci (1996) 16:2508-21.

28. Domercq M, Vazquez N, Matute C. Neurotransmitter signaling in the pathophysiology of microglia. Front Cell Neurosci (2013) 7:49. doi:10.3389/ fncel.2013.00049

29. Palmer AM. Multiple sclerosis and the blood-central nervous system barrier. Cardiovasc Psychiatry Neurol (2013) 2013:530356. doi:10.1155/ 2013/530356

30. Erickson MA, Dohi K, Banks WA. Neuroinflammation: a common pathway in CNS diseases as mediated at the blood-brain barrier. Neuroimmunomodulation (2012) 19:121-30. doi:10.1159/000330247

31. Erny D, Hrabě de Angelis AL, Jaitin D, Wieghofer P, Staszewski O, David E, et al. Host microbiota constantly control maturation and function of microglia in the CNS. Nat Neurosci (2015) 18:965-77. doi:10.1038/nn.4030

32. Sherwin E, Rea K, Dinan TG, Cryan JF. A gut (microbiome) feeling about the brain. Curr Opin Gastroenterol (2016) 32:96-102. doi:10.1097/ MOG.0000000000000244

33. Burokas A, Moloney RD, Dinan TG, Cryan JF. Microbiota regulation of the mammalian gut-brain axis. Adv Appl Microbiol (2015) 91:1-62. doi:10.1016/ bs.aambs.2015.02.001

34. Kelly JR, Kennedy PJ, Cryan JF, Dinan TG, Clarke G, Hyland NP. Breaking down the barriers: the gut microbiome, intestinal permeability and stressrelated psychiatric disorders. Front Cell Neurosci (2015) 9:392. doi:10.3389/ fncel.2015.00392

35. Malik M, Parikh I, Vasquez JB, Smith C, Tai L, Bu G, et al. Genetics ignite focus on microglial inflammation in Alzheimer's disease. Mol Neurodegener (2015) 10:52. doi:10.1186/s13024-015-0048-1

36. Cai D. Neuroinflammation and neurodegeneration in overnutritioninduced diseases. Trends Endocrinol Metab (2013) 24:40-7. doi:10.1016/j. tem.2012.11.003

37. Block ML, Calderón-Garcidueñas L. Air pollution: mechanisms of neuroinflammation and CNS disease. Trends Neurosci (2009) 32:506-16. doi:10.1016/j.tins.2009.05.009

38. Timmermans S, Bogie JFJ, Vanmierlo T, Lütjohann D, Stinissen P, Hellings $\mathrm{N}$, et al. High fat diet exacerbates neuroinflammation in an animal model of multiple sclerosis by activation of the renin angiotensin system. J Neuroimmune Pharmacol (2014) 9:209-17. doi:10.1007/ s11481-013-9502-4

39. Castanon N, Luheshi G, Layé S. Role of neuroinflammation in the emotional and cognitive alterations displayed by animal models of obesity. Front Neurosci (2015) 9:229. doi:10.3389/fnins.2015.00229

40. De Souza CT, Araujo EP, Bordin S, Ashimine R, Zollner RL, Boschero AC, et al. Consumption of a fat-rich diet activates a proinflammatory response and induces insulin resistance in the hypothalamus. Endocrinology (2005) 146:4192-9. doi:10.1210/en.2004-1520

41. Valdearcos M, Xu AW, Koliwad SK. Hypothalamic inflammation in the control of metabolic function. Annu Rev Physiol (2015) 77:131-60. doi:10.1146/ annurev-physiol-021014-071656

42. Morris MC. Nutrition and risk of dementia: overview and methodological issues. Ann N Y Acad Sci (2016) 1367:31-7. doi:10.1111/nyas.13047

43. Riffel APK, de Souza JA, Santos Mdo CQ, Horst A, Scheid T, Kolberg C, et al. Systemic administration of vitamins $\mathrm{C}$ and $\mathrm{E}$ attenuates nociception induced by chronic constriction injury of the sciatic nerve in rats. Brain Res Bull (2016) 121:169-77. doi:10.1016/j.brainresbull.2016.02.004

44. Barañano KW, Hartman AL. The ketogenic diet: uses in epilepsy and other neurologic illnesses. Curr Treat Options Neurol (2008) 10:410-9. doi:10.1007/ s1 1940-008-0043-8 
45. Lutas A, Yellen G. The ketogenic diet: metabolic influences on brain excitability and epilepsy. Trends Neurosci (2013) 36:32-40. doi:10.1016/j. tins.2012.11.005

46. Dupuis N, Curatolo N, Benoist J-F, Auvin S. Ketogenic diet exhibits anti-inflammatory properties. Epilepsia (2015) 56:e95-8. doi:10.1111/epi. 13038

47. Rahman M, Muhammad S, Khan MA, Chen H, Ridder DA, Müller-Fielitz H, et al. The $\beta$-hydroxybutyrate receptor HCA2 activates a neuroprotective subset of macrophages. Nat Commun (2014) 5:3944. doi:10.1038/ncomms4944

48. Offermanns S, Schwaninger M. Nutritional or pharmacological activation of HCA2 ameliorates neuroinflammation. Trends Mol Med (2015) 21:245-55. doi:10.1016/j.molmed.2015.02.002

49. Youm Y-H, Nguyen KY, Grant RW, Goldberg EL, Bodogai M, Kim D, et al. The ketone metabolite $\beta$-hydroxybutyrate blocks NLRP3 inflammasomemediated inflammatory disease. Nat Med (2015) 21:263-9. doi:10.1038/ nm.3804

50. Seyfried TN, Flores R, Poff AM, D’Agostino DP, Mukherjee P. Metabolic therapy: a new paradigm for managing malignant brain cancer. Cancer Lett (2015) 356:289-300. doi:10.1016/j.canlet.2014.07.015

51. Hertz L, Chen Y, Waagepetersen HS. Effects of ketone bodies in Alzheimer's disease in relation to neural hypometabolism, $\beta$-amyloid toxicity, and astrocyte function. J Neurochem (2015) 134:7-20. doi:10.1111/jnc.13107

52. Woolf EC, Scheck AC. The ketogenic diet for the treatment of malignant glioma. J Lipid Res (2015) 56:5-10. doi:10.1194/jlr.R046797

53. Wright C, Simone NL. Obesity and tumor growth: inflammation, immunity, and the role of a ketogenic diet. Curr Opin Clin Nutr Metab Care (2016) 19(4):294-9. doi:10.1097/MCO.0000000000000286

54. Kohli P, Levy BD. Resolvins and protectins: mediating solutions to inflammation.BrJ Pharmacol(2009)158:960-71.doi:10.1111/j.1476-5381.2009.00290.x

55. Li L, Wu Y, Wang Y, Wu J, Song L, Xian W, et al. Resolvin D1 promotes the interleukin-4-induced alternative activation in BV-2 microglial cells. J Neuroinflammation (2014) 11:72. doi:10.1186/1742-2094-11-72

56. Orr SK, Palumbo S, Bosetti F, Mount HT, Kang JX, Greenwood CE, et al. Unesterified docosahexaenoic acid is protective in neuroinflammation. J Neurochem (2013) 127:378-93. doi:10.1111/jnc.12392

57. Chang C-Y, Kuan Y-H, Li J-R, Chen W-Y, Ou Y-C, Pan H-C, et al. Docosahexaenoic acid reduces cellular inflammatory response following permanent focal cerebral ischemia in rats. J Nutr Biochem (2013) 24:2127-37. doi:10.1016/j.jnutbio.2013.08.004

58. Orr SK, Trépanier M-O, Bazinet RP. n-3 Polyunsaturated fatty acids in animal models with neuroinflammation. Prostaglandins Leukot Essent Fatty Acids (2013) 88:97-103. doi:10.1016/j.plefa.2012.05.008

59. Chang PK-Y, Khatchadourian A, McKinney RA, Maysinger D. Docosahexaenoic acid (DHA): a modulator of microglia activity and dendritic spine morphology. J Neuroinflammation (2015) 12:34. doi:10.1186/ s12974-015-0244-5

60. Tremblay M-E, Zhang I, Bisht K, Savage JC, Lecours C, Parent M, et al. Remodeling of lipid bodies by docosahexaenoic acid in activated microglial cells. J Neuroinflammation (2016) 13:116. doi:10.1186/s12974-016-0580-0

61. Welte MA. How brain fat conquers stress. Cell (2015) 163:269-70. doi:10.1016/j.cell.2015.09.046

62. Bailey AP, Koster G, Guillermier C, Hirst EMA, MacRae JI, Lechene CP, et al. Antioxidant role for lipid droplets in a stem cell niche of Drosophila. Cell (2015) 163:340-53. doi:10.1016/j.cell.2015.09.020

63. Ríos-Covián D, Ruas-Madiedo P, Margolles A, Gueimonde M, de los Reyes-Gavilán CG, Salazar N. Intestinal short chain fatty acids and their link with diet and human health. Front Microbiol (2016) 7:185. doi:10.3389/ fmicb.2016.00185

64. Tilg $\mathrm{H}$, Adolph TE. Influence of the human intestinal microbiome on obesity and metabolic dysfunction. Curr Opin Pediatr (2015) 27:496-501. doi:10.1097/MOP.0000000000000234

65. Chu H, Mazmanian SK. Winning the microbial battle, but not the war. Cell (2015) 163:271-2. doi:10.1016/j.cell.2015.09.050

66. Canfora EE, Jocken JW, Blaak EE. Short-chain fatty acids in control of body weight and insulin sensitivity. Nat Rev Endocrinol (2015) 11:577-91. doi:10.1038/nrendo.2015.128

67. Braniste V, Al-Asmakh M, Kowal C, Anuar F, Abbaspour A, Tóth M, et al. The gut microbiota influences blood-brain barrier permeability in mice. Sci Transl Med (2014) 6:263ra158. doi:10.1126/scitranslmed.3009759
68. Frost G, Sleeth ML, Sahuri-Arisoylu M, Lizarbe B, Cerdan S, Brody L, et al. The short-chain fatty acid acetate reduces appetite via a central homeostatic mechanism. Nat Commun (2014) 5:3611. doi:10.1038/ncomms4611

69. Sudo N, Chida Y, Aiba Y, Sonoda J, Oyama N, Yu X-N, et al. Postnatal microbial colonization programs the hypothalamic-pituitary-adrenal system for stress response in mice. J Physiol (2004) 558:263-75. doi:10.1113/ jphysiol.2004.063388

70. Bercik P, Collins SM. The effects of inflammation, infection and antibiotics on the microbiota-gut-brain axis. Adv Exp Med Biol (2014) 817:279-89. doi:10.1007/978-1-4939-0897-4_13

71. Dinan TG, Stanton C, Cryan JF. Psychobiotics: a novel class of psychotropic. Biol Psychiatry (2013) 74:720-6. doi:10.1016/j.biopsych.2013.05.001

72. Dobrovolskaia MA, McNeil SE. Immunological properties of engineered nanomaterials. Nat Nanotechnol (2007) 2:469-78. doi:10.1038/ nnano.2007.223

73. Colvin VL. The potential environmental impact of engineered nanomaterials. Nat Biotechnol (2003) 21:1166-70. doi:10.1038/nbt875

74. Frampton MW, Brauer M, Kleeman M, Kreyling WG, Ntziachristos L, Sarnat $\mathrm{SE}$, et al. Understanding the Health Effects of Ambient Ultrafine Particles. Boston, MA: Health Effects Institute (2013).

75. Zhang L, Webster TJ. Nanotechnology and nanomaterials: promises for improved tissue regeneration. Nano Today (2009) 4:66-80. doi:10.1016/j. nantod.2008.10.014

76. Liu H, Webster TJ. Nanomedicine for implants: a review of studies and necessary experimental tools. Biomaterials (2007) 28:354-69. doi:10.1016/j. biomaterials.2006.08.049

77. Ghanbari H, de Mel A, Seifalian AM. Cardiovascular application of polyhedral oligomeric silsesquioxane nanomaterials: a glimpse into prospective horizons. Int J Nanomedicine (2011) 6:775-86. doi:10.2147/IJN.S14881

78. Shevach M, Fleischer S, Shapira A, Dvir T. Gold nanoparticle-decellularized matrix hybrids for cardiac tissue engineering. Nano Lett (2014) 14:5792-6. doi:10.1021/nl502673m

79. Gustafson HH, Holt-Casper D, Grainger DW, Ghandehari H. Nanoparticle uptake: the phagocyte problem. Nano Today (2015) 10:487-510. doi:10.1016/j. nantod.2015.06.006

80. Kagan VE, Konduru NV, Feng W, Allen BL, Conroy J, Volkov Y, et al. Carbon nanotubes degraded by neutrophil myeloperoxidase induce less pulmonary inflammation. Nat Nanotechnol (2010) 5:354-9. doi:10.1038/nnano.2010.44

81. Park MVDZ, Neigh AM, Vermeulen JP, de la Fonteyne LJJ, Verharen HW, Briedé JJ, et al. The effect of particle size on the cytotoxicity, inflammation, developmental toxicity and genotoxicity of silver nanoparticles. Biomaterials (2011) 32:9810-7. doi:10.1016/j.biomaterials.2011.08.085

82. Park E-J, Yoon J, Choi K, Yi J, Park K. Induction of chronic inflammation in mice treated with titanium dioxide nanoparticles by intratracheal instillation. Toxicology (2009) 260:37-46. doi:10.1016/j.tox.2009.03.005

83. Ilinskaya AN, Dobrovolskaia MA. Understanding the immunogenicity and antigenicity of nanomaterials: past, present and future. Toxicol Appl Pharmacol (2016) 299:70-7. doi:10.1016/j.taap.2016.01.005

84. Longmire M, Choyke PL, Kobayashi H. Clearance properties of nano-sized particles and molecules as imaging agents: considerations and caveats. Nanomedicine (Lond) (2008) 3:703-17. doi:10.2217/17435889.3.5.703

85. Park HJ, Sohn J-H, Kim Y-J, Park YH, Han H, Park KH, et al. Acute exposure to silica nanoparticles aggravate airway inflammation: different effects according to surface characteristics. Exp Mol Med (2015) 47:e173. doi:10.1038/emm.2015.50

86. Dobrovolskaia MA. Pre-clinical immunotoxicity studies of nanotechnology-formulated drugs: challenges, considerations and strategy. J Control Release (2015) 220:571-83. doi:10.1016/j.jconrel.2015.08.056

87. Yanamala N, Kagan VE, Shvedova AA. Molecular modeling in structural nano-toxicology: interactions of nano-particles with nano-machinery of cells. Adv Drug Deliv Rev (2013) 65:2070-7. doi:10.1016/j.addr.2013.05.005

88. Papa S, Ferrari R, De Paola M, Rossi F, Mariani A, Caron I, et al. Polymeric nanoparticle system to target activated microglia/macrophages in spinal cord injury. J Control Release (2014) 174:15-26. doi:10.1016/j.jconrel. 2013.11.001

89. Cerqueira SR, Oliveira JM, Silva NA, Leite-Almeida H, Ribeiro-Samy S, Almeida A, et al. Microglia response and in vivo therapeutic potential of methylprednisolone-loaded dendrimer nanoparticles in spinal cord injury. Small (2013) 9:738-49. doi:10.1002/smll.201201888 
90. Hambardzumyan D, Gutmann DH, Kettenmann H. The role of microglia and macrophages in glioma maintenance and progression. Nat Neurosci (2016) 19:20-7. doi:10.1038/nn.4185

91. Louveau A, Smirnov I, Keyes TJ, Eccles JD, Rouhani SJ, Peske JD, et al. Structural and functional features of central nervous system lymphatic vessels. Nature (2015) 523:337-41. doi:10.1038/nature14432

92. Yi L, Xiao H, Xu M, Ye X, Hu J, Li F, et al. Glioma-initiating cells: a predominant role in microglia/macrophages tropism to glioma. J Neuroimmunol (2011) 232:75-82. doi:10.1016/j.jneuroim.2010.10.011

93. Lapa C, Linsenmann T, Lückerath K, Samnick S, Herrmann K, Stoffer C, et al. Tumor-associated macrophages in glioblastoma multiforme - a suitable target for somatostatin receptor-based imaging and therapy? PLoS One (2015) 10:e0122269. doi:10.1371/journal.pone.0122269

94. Szulzewsky F, Pelz A, Feng X, Synowitz M, Markovic D, Langmann T, et al. Glioma-associated microglia/macrophages display an expression profile different from M1 and M2 polarization and highly express Gpnmb and Spp1. PLoS One (2015) 10:e116644. doi:10.1371/journal.pone.0116644

95. Zhou B-BS, Zhang H, Damelin M, Geles KG, Grindley JC, Dirks PB. Tumourinitiating cells: challenges and opportunities for anticancer drug discovery. Nat Rev Drug Discov (2009) 8:806-23. doi:10.1038/nrd2137

96. Chen K, Huang Y, Chen J. Understanding and targeting cancer stem cells: therapeutic implications and challenges. Acta Pharmacol Sin (2013) 34:732-40. doi:10.1038/aps.2013.27

97. Bao S, Wu Q, McLendon RE, Hao Y, Shi Q, Hjelmeland AB, et al. Glioma stem cells promote radioresistance by preferential activation of the DNA damage response. Nature (2006) 444:756-60. doi:10.1038/nature05236

98. Hambardzumyan D, Squatrito M, Holland EC. Radiation resistance and stem-like cells in brain tumors. Cancer Cell (2007) 11:97. doi:10.1016/j. ccr.2006.12.011

99. Tokudome T, Sasaki A, Tsuji M, Udaka Y, Oyamada H, Tsuchiya H, et al. Reduced PTEN expression and overexpression of miR-17-5p, -19a-3p, $-19 b-3 p,-21-5 p,-130 b-3 p,-221-3 p$ and $-222-3 p$ by glioblastoma stem-like cells following irradiation. Oncol Lett (2015) 10:2269-72. doi:10.3892/ol. 2015.3594

100. Combs SE, Schmid TE, Vaupel P, Multhoff G. Stress response leading to resistance in glioblastoma - the need for innovative radiotherapy (iRT) concepts. Cancers (Basel) (2016) 8:15. doi:10.3390/cancers 8010015

101. Allen BG, Bhatia SK, Anderson CM, Eichenberger-Gilmore JM, Sibenaller ZA, Mapuskar KA, et al. Ketogenic diets as an adjuvant cancer therapy: history and potential mechanism. Redox Biol (2014) 2:963-70. doi:10.1016/j. redox.2014.08.002

102. Staedtke V, Bai R-Y, Laterra J. Investigational new drugs for brain cancer. Expert Opin Investig Drugs (2016) 1-20. doi:10.1080/13543784.2016. 1182497

103. Getts DR, Shea LD, Miller SD, King NJC. Harnessing nanoparticles for immune modulation. Trends Immunol (2015) 36:419-27. doi:10.1016/j. it.2015.05.007

104. Niu M, Naguib YW, Aldayel AM, Shi Y, Hursting SD, Hersh MA, et al. Biodistribution and in vivo activities of tumor-associated macrophage-targeting nanoparticles incorporated with doxorubicin. Mol Pharm (2014) 11:4425-36. doi:10.1021/mp500565q

105. Zhu S, Niu M, O’Mary H, Cui Z. Targeting of tumor-associated macrophages made possible by PEG-sheddable, mannose-modified nanoparticles. $\mathrm{Mol}$ Pharm (2013) 10:3525-30. doi:10.1021/mp400216r

106. Heek T, Kühne C, Depner H, Achazi K, Dernedde J, Haag R. Synthesis, photophysical, and biological evaluation of sulfated polyglycerol dendronized perylenebisimides (PBIs)-a promising platform for anti-inflammatory theranostic agents? Bioconjug Chem (2016) 27(3):727-36. doi:10.1021/acs. bioconjchem.5b00683

107. Reimann S, Gröger D, Kühne C, Riese SB, Dernedde J, Haag R. Shell cleavable dendritic polyglycerol sulfates show high anti-inflammatory properties by inhibiting L-selectin binding and complement activation. Adv Healthc Mater (2015) 4(14):2154-62. doi:10.1002/adhm.201500503

108. Maysinger D, Gröger D, Lake A, Licha K, Weinhart M, Chang PK-Y, et al. Dendritic polyglycerol sulfate inhibits microglial activation and reduces hippocampal CA1 dendritic spine morphology deficits. Biomacromolecules (2015) 16:3073-82. doi:10.1021/acs.biomac.5b00999

109. Getts DR, Terry RL, Getts MT, Deffrasnes C, Müller M, van Vreden C, et al. Therapeutic inflammatory monocyte modulation using immune-modifying microparticles. Sci Transl Med (2014) 6:219ra7. doi:10.1126/ scitranslmed.3007563

110. Smith MJ, Brown JM, Zamboni WC, Walker NJ. From immunotoxicity to nanotherapy: the effects of nanomaterials on the immune system. Toxicol Sci (2014) 138:249-55. doi:10.1093/toxsci/kfu005

111. Kettenmann H, Hanisch U-K, Noda M, Verkhratsky A. Physiology of microglia. Physiol Rev (2011) 91:461-553. doi:10.1152/physrev.00011.2010

112. Tambuyzer BR, Ponsaerts P, Nouwen EJ. Microglia: gatekeepers of central nervous system immunology. J Leukoc Biol (2009) 85:352-70. doi:10.1189/ jlb.0608385

113. Jones EV, Cook D, Murai KK. A neuron-astrocyte co-culture system to investigate astrocyte-secreted factors in mouse neuronal development. Methods Mol Biol (2012) 814:341-52. doi:10.1007/978-1-61779-452-0_22

114. Rodhe J. Cell culturing of human and murine microglia cell lines. In: Joseph B, Venero JL, editors. Microglia Methods in Molecular Biology. New York: Humana Press (2013). p. 11-6.

115. Gresa-Arribas N, Viéitez C, Dentesano G, Serratosa J, Saura J, Solà C. Modelling neuroinflammation in vitro: a tool to test the potential neuroprotective effect of anti-inflammatory agents. PLoS One (2012) 7:e45227. doi:10.1371/journal.pone.0045227

116. Saura J. Microglial cells in astroglial cultures: a cautionary note. J Neuroinflammation (2007) 4:26. doi:10.1186/1742-2094-4-26

117. Pluchino S, Zanotti L, Rossi B, Brambilla E, Ottoboni L, Salani G, et al. Neurosphere-derived multipotent precursors promote neuroprotection by an immunomodulatory mechanism. Nature (2005) 436:266-71. doi:10.1038/ nature03889

118. Pluchino S, Muzio L, Imitola J, Deleidi M, Alfaro-Cervello C, Salani G, et al. Persistent inflammation alters the function of the endogenous brain stem cell compartment. Brain (2008) 131:2564-78. doi:10.1093/brain/awn198

119. Li L, Walker TL, Zhang Y, Mackay EW, Bartlett PF. Endogenous interferon $\gamma$ directly regulates neural precursors in the non-inflammatory brain. J Neurosci (2010) 30:9038-50. doi:10.1523/JNEUROSCI.5691-09.2010

120. Cho S, Wood A, Bowlby MR. Brain slices as models for neurodegenerative disease and screening platforms to identify novel therapeutics. Curr Neuropharmacol (2007) 5:19-33. doi:10.2174/157015907780077105

121. Huuskonen J, Suuronen T, Miettinen R, van Groen T, Salminen A. A refined in vitro model to study inflammatory responses in organotypic membrane culture of postnatal rat hippocampal slices. J Neuroinflammation (2005) 2:25. doi:10.1186/1742-2094-2-25

122. Humpel C. Organotypic brain slice cultures: a review. Neuroscience (2015) 305:86-98. doi:10.1016/j.neuroscience.2015.07.086

123. De Simoni A, Yu L. Preparation of organotypic hippocampal slice cultures: interface method. Nat Protoc (2006) 1:1439-45. doi:10.1038/nprot.2006.228

124. Ting JT, Daigle TL, Chen Q, Feng G. Acute brain slice methods for adult and aging animals: application of targeted patch clampanalysis and optogenetics. Methods Mol Biol (2014) 1183:221-42. doi:10.1007/978-1-4939-1096-0_14

125. Mishra A, O'Farrell FM, Reynell C, Hamilton NB, Hall CN, Attwell D. Imaging pericytes and capillary diameter in brain slices and isolated retinae. Nat Protoc (2014) 9:323-36. doi:10.1038/nprot.2014.019

126. Buskila Y, Breen PP, Tapson J, van Schaik A, Barton M, Morley JW. Extending the viability of acute brain slices. Sci Rep (2014) 4:5309. doi:10.1038/srep05309

127. Oosterhof N, Boddeke E, van Ham TJ. Immune cell dynamics in the CNS: learning from the zebrafish. Glia (2015) 63:719-35. doi:10.1002/glia.22780

128. Buckwalter MS, Wyss-Coray T. Modelling neuroinflammatory phenotypes in vivo. J Neuroinflammation (2004) 1:10. doi:10.1186/1742-2094-1-10

129. Nazem A, Sankowski R, Bacher M, Al-Abed Y. Rodent models of neuroinflammation for Alzheimer's disease. J Neuroinflammation (2015) 12:74. doi:10.1186/s12974-015-0291-y

130. Cazareth J, Guyon A, Heurteaux C, Chabry J, Petit-Paitel A. Molecular and cellular neuroinflammatory status of mouse brain after systemic lipopolysaccharide challenge: importance of CCR2/CCL2 signaling. J Neuroinflammation (2014) 11:132. doi:10.1186/1742-2094-11-132

131. McCarthy RC, Lu D-Y, Alkhateeb A, Gardeck AM, Lee C-H, WesslingResnick M. Characterization of a novel adult murine immortalized microglial cell line and its activation by amyloid-beta. J Neuroinflammation (2016) 13:21. doi:10.1186/s12974-016-0484-Z

132. Butovsky O, Jedrychowski MP, Moore CS, Cialic R, Lanser AJ, Gabriely G, et al. Identification of a unique TGF- $\beta$-dependent molecular and functional signature in microglia. Nat Neurosci (2014) 17:131-43. doi:10.1038/nn.3599 
133. Greter M, Lelios I, Croxford AL. Microglia versus myeloid cell nomenclature during brain inflammation. Front Immunol (2015) 6:249. doi:10.3389/ fimmu.2015.00249

134. Morrison B III, Elkin BS, Dollé J-P, Yarmush ML. In vitro models of traumatic brain injury. Annu Rev Biomed Eng (2011) 13:91-126. doi:10.1146/ annurev-bioeng-071910-124706

135. Tang S-C, Arumugam TV, Xu X, Cheng A, Mughal MR, Jo DG, et al. Pivotal role for neuronal toll-like receptors in ischemic brain injury and functional deficits. Proc Natl Acad Sci U S A (2007) 104:13798-803. doi:10.1073/ pnas.0702553104

136. Latz E, Xiao TS, Stutz A. Activation and regulation of the inflammasomes. Nat Rev Immunol (2013) 13:397-411. doi:10.1038/nri3452

137. Gurung P, Lukens JR, Kanneganti T-D. Mitochondria: diversity in the regulation of the NLRP3 inflammasome. Trends Mol Med (2015) 21:193-201. doi:10.1016/j.molmed.2014.11.008

138. Hua K-F, Chou J-C, Ka S-M, Tasi Y-L, Chen A, Wu S-H, et al. Cyclooxygenase-2 regulates NLRP3 inflammasome-derived IL-1 $\beta$ production. J Cell Physiol (2015) 230:863-74. doi:10.1002/jcp.24815

139. Savage CD, Lopez-Castejon G, Denes A, Brough D. NLRP3-inflammasome activating DAMPs stimulate an inflammatory response in glia in the absence of priming which contributes to brain inflammation after injury. Inflammation (2012) 3:288. doi:10.3389/fimmu.2012.00288

140. Goldmann T, Tay TL, Prinz M. Love and death: microglia, NLRP3 and the Alzheimer's brain. Cell Res (2013) 23:595-6. doi:10.1038/cr.2013.24

141. Gustin A, Kirchmeyer M, Koncina E, Felten P, Losciuto S, Heurtaux T, et al. NLRP3 inflammasome is expressed and functional in mouse brain microglia but not in astrocytes. PLoS One (2015) 10:e0130624. doi:10.1371/journal. pone. 0130624

142. Liu H-D, Li W, Chen Z-R, Hu Y-C, Zhang D-D, Shen W, et al. Expression of the NLRP3 inflammasome in cerebral cortex after traumatic brain injury in a rat model. Neurochem Res (2013) 38:2072-83. doi:10.1007/s11064-013-1115-Z

143. Jha S, Srivastava SY, Brickey WJ, Iocca H, Toews A, Morrison JP, et al. The inflammasome sensor, NLRP3, regulates CNS inflammation and demyelination via caspase-1 and interleukin-18. J Neurosci (2010) 30:15811-20. doi:10.1523/JNEUROSCI.4088-10.2010

144. Tovar-Y-Romo LB, Penagos-Puig A, Ramírez-Jarquín JO. Endogenous recovery after brain damage: molecular mechanisms that balance neuronal life/death fate. J Neurochem (2016) 136:13-27. doi:10.1111/jnc.13362

145. Tan M-S, Tan L, Jiang T, Zhu X-C, Wang H-F, Jia C-D, et al. Amyloid- $\beta$ induces NLRP1-dependent neuronal pyroptosis in models of Alzheimer's disease. Cell Death Dis (2014) 5:e1382. doi:10.1038/cddis.2014.348

146. Sagulenko V, Thygesen SJ, Sester DP, Idris A, Cridland JA, Vajjhala PR, et al. AIM2 and NLRP3 inflammasomes activate both apoptotic and pyroptotic death pathways via ASC. Cell Death Differ (2013) 20:1149-60. doi:10.1038/ cdd.2013.37

147. Scheller J, Chalaris A, Schmidt-Arras D, Rose-John S. The pro- and anti-inflammatory properties of the cytokine interleukin-6. Biochim Biophys Acta (2011) 1813:878-88. doi:10.1016/j.bbamcr.2011.01.034

148. Smith JA, Das A, Ray SK, Banik NL. Role of pro-inflammatory cytokines released from microglia in neurodegenerative diseases. Brain Res Bull (2012) 87:10-20. doi:10.1016/j.brainresbull.2011.10.004

149. Scheller J, Garbers C, Rose-John S. Interleukin-6: from basic biology to selective blockade of pro-inflammatory activities. Semin Immunol (2014) 26:2-12. doi:10.1016/j.smim.2013.11.002

150. Schaper F, Rose-John S. Interleukin-6: biology, signaling and strategies of blockade. Cytokine Growth Factor Rev (2015) 26:475-87. doi:10.1016/j. cytogfr.2015.07.004

151. Hong S-S, Choi JH, Lee SY, Park Y-H, Park K-Y, Lee JY, et al. A novel small-molecule inhibitor targeting the IL- 6 receptor $\beta$ subunit, glycoprotein 130. J Immunol (2015) 195:237-45. doi:10.4049/jimmunol.1402908

152. Rivest S. Molecular insights on the cerebral innate immune system. Brain Behav Immun (2003) 17:13-9. doi:10.1016/S0889-1591(02)00055-7

153. Espinosa-Oliva AM, de Pablos RM, Herrera AJ. Intracranial injection of LPS in rat as animal model of neuroinflammation. Methods Mol Biol (2013) 1041:295-305. doi:10.1007/978-1-62703-520-0_26

154. Opal SM, Laterre P-F, Francois B, LaRosa SP, Angus DC, Mira J-P, et al. Effect of eritoran, an antagonist of MD2-TLR4, on mortality in patients with severe sepsis: the ACCESS randomized trial. JAMA (2013) 309:1154-62. doi:10.1001/jama.2013.2194
155. Smith C, Wang X, Yin H. Caspases come together over LPS. Trends Immunol (2015) 36:59-61. doi:10.1016/j.it.2014.12.007

156. Galluzzi L, López-Soto A, Kumar S, Kroemer G. Caspases connect celldeath signaling to organismal homeostasis. Immunity (2016) 44:221-31. doi:10.1016/j.immuni.2016.01.020

157. Shi J, Zhao Y, Wang Y, Gao W, Ding J, Li P, et al. Inflammatory caspases are innate immune receptors for intracellular LPS. Nature (2014) 514:187-92. doi:10.1038/nature13683

158. Yokoo H, Chiba S, Tomita K, Takashina M, Sagara H, Yagisita S, et al. Neurodegenerative evidence in mice brains with cecal ligation and puncture-induced sepsis: preventive effect of the free radical scavenger edaravone. PLoS One (2012) 7:e51539. doi:10.1371/journal.pone.0051539

159. Dejager L, Pinheiro I, Dejonckheere E, Libert C. Cecal ligation and puncture: the gold standard model for polymicrobial sepsis? Trends Microbiol (2011) 19:198-208. doi:10.1016/j.tim.2011.01.001

160. Rittirsch D, Huber-Lang MS, Flierl MA, Ward PA. Immunodesign of experimental sepsis by cecal ligation and puncture. Nat Protoc (2009) 4:31-6. doi:10.1038/nprot.2008.214

161. Sawyer RG. Surgical Infections, An Issue of Surgical Clinics. Philadelphia, PA: Elsevier Health Sciences (2015).

162. Jankowsky JL, Slunt HH, Ratovitski T, Jenkins NA, Copeland NG, Borchelt DR. Co-expression of multiple transgenes in mouse CNS: a comparison of strategies. Biomol Eng (2001) 17:157-65. doi:10.1016/ S1389-0344(01)00067-3

163. Kumar DKV, Choi SH, Washicosky KJ, Eimer WA, Tucker S, Ghofrani J, et al. Amyloid- $\beta$ peptide protects against microbial infection in mouse and worm models of Alzheimer's disease. Sci Transl Med (2016) 8:340ra72. doi:10.1126/ scitranslmed.aaf1059

164. St Martin JL, Klucken J, Outeiro TF, Nguyen P, Keller-McGandy C, CantutiCastelvetri I, et al. Dopaminergic neuron loss and up-regulation of chaperone protein mRNA induced by targeted over-expression of alpha-synuclein in mouse substantia nigra. J Neurochem (2007) 100:1449-57. doi:10.1111/j.14714159.2006.04310.x

165. Gurney ME, Pu H, Chiu AY, Dal Canto MC, Polchow CY, Alexander DD, et al. Motor neuron degeneration in mice that express a human $\mathrm{Cu}, \mathrm{Zn}$ superoxide dismutase mutation. Science (1994) 264:1772-5. doi:10.1126/ science. 8209258

166. Wong PC, Pardo CA, Borchelt DR, Lee MK, Copeland NG, Jenkins NA, et al An adverse property of a familial ALS-linked SOD1 mutation causes motor neuron disease characterized by vacuolar degeneration of mitochondria. Neuron (1995) 14:1105-16. doi:10.1016/0896-6273(95)90259-7

167. Kozai TDY, Li X, Bodily LM, Caparosa EM, Zenonos GA, Carlisle DL, et al. Effects of caspase-1 knockout on chronic neural recording quality and longevity: insight into cellular and molecular mechanisms of the reactive tissue response. Biomaterials (2014) 35:9620-34. doi:10.1016/j.biomaterials.2014. 08.006

168. Swiech L, Heidenreich M, Banerjee A, Habib N, Li Y, Trombetta J, et al. In vivo interrogation of gene function in the mammalian brain using CRISPR-Cas9. Nat Biotechnol (2015) 33:102-6. doi:10.1038/ nbt.3055

169. Yen S-T, Zhang M, Deng JM, Usman SJ, Smith CN, Parker-Thornburg J, et al. Somatic mosaicism and allele complexity induced by CRISPR/Cas 9 RNA injections in mouse zygotes. Dev Biol (2014) 393:3-9. doi:10.1016/j. ydbio.2014.06.017

170. Maysinger D, Ji J, Hutter E, Cooper E. Nanoparticle-based and bioengineered probes and sensors to detect physiological and pathological biomarkers in neural cells. Front Neurosci (2015) 9:480. doi:10.3389/fnins. 2015.00480

171. Mossakowski AA, Pohlan J, Bremer D, Lindquist R, Millward JM, Bock M, et al. Tracking CNS and systemic sources of oxidative stress during the course of chronic neuroinflammation. Acta Neuropathol (2015) 130:799-814. doi:10.1007/s00401-015-1497-x

172. Radbruch H, Bremer D, Mothes R, Günther R, Rinnenthal JL, Pohlan J, et al. Intravital FRET: probing cellular and tissue function in vivo. Int J Mol Sci (2015) 16:11713-27. doi:10.3390/ijms160511713

173. Zhang F, Mastorakos P, Mishra MK, Mangraviti A, Hwang L, Zhou J, et al. Uniform brain tumor distribution and tumor associated macrophage targeting of systemically administered dendrimers. Biomaterials (2015) 52:507-16. doi:10.1016/j.biomaterials.2015.02.053 
174. Spitzer N, Sammons GS, Price EM. Autofluorescent cells in rat brain can be convincing impostors in green fluorescent reporter studies. J Neurosci Methods (2011) 197:48-55. doi:10.1016/j.jneumeth.2011.01.029

175. Neumann M, Gabel D. Simple method for reduction of autofluorescence in fluorescence microscopy. J Histochem Cytochem (2002) 50:437-9. doi: $10.1177 / 002215540205000315$

176. Goldey GJ, Roumis DK, Glickfeld LL, Kerlin AM, Reid RC, Bonin V, et al. Removable cranial windows for long-term imaging in awake mice. Nat Protoc (2014) 9:2515-38. doi:10.1038/nprot.2014.165

177. Holtmaat A, Bonhoeffer T, Chow DK, Chuckowree J, De Paola V, Hofer SB, et al. Long-term, high-resolution imaging in the mouse neocortex through a chronic cranial window. Nat Protoc (2009) 4:1128-44. doi:10.1038/ nprot.2009.89

178. Dorand RD, Barkauskas DS, Evans TA, Petrosiute A, Huang AY. Comparison of intravital thinned skull and cranial window approaches to study CNS immunobiology in the mouse cortex. Intravital (2014) 3:e29728. doi:10.4161/ intv.29728

179. Yang G, Pan F, Parkhurst CN, Grutzendler J, Gan W-B. Thinned-skull cranial window technique for long-term imaging of the cortex in live mice. Nat Protoc (2010) 5:201-8. doi:10.1038/nprot.2009.222

180. Yu X, Zuo Y. Two-photon in vivo imaging of dendritic spines in the mouse cortex using a thinned-skull preparation. J Vis Exp (2014) (87):e51520. doi: $10.3791 / 51520$

181. Aswendt M, Adamczak J, Couillard-Despres S, Hoehn M. Boosting bioluminescence neuroimaging: an optimized protocol for brain studies. PLoS One (2013) 8:e55662. doi:10.1371/journal.pone.0055662

182. Cordeau P, Lalancette-Hébert M, Weng YC, Kriz J. Estrogen receptors alpha mediates postischemic inflammation in chronically estrogen-deprived mice. Neurobiol Aging (2016) 40:50-60. doi:10.1016/j.neurobiolaging. 2016.01.002

183. Dany Arsenault JD-O. A novel combinational approach of microstimulation and bioluminescence imaging to study the mechanisms of action of cerebral electrical stimulation in mice: stimulation device for small animals. J Physiol (2015) 593(Pt 10):2257-78. doi:10.1113/jphysiol.2014.287243

184. Lalancette-Hébert M, Moquin A, Choi AO, Kriz J, Maysinger D. Lipopolysaccharide-QD micelles induce marked induction of TLR2 and lipid droplet accumulation in olfactory bulb microglia. Mol Pharm (2010) 7:1183-94. doi:10.1021/mp1000372

185. Moquin A, Hutter E, Choi AO, Khatchadourian A, Castonguay A, Winnik FM, et al. Caspase-1 activity in microglia stimulated by pro-inflammagen nanocrystals. ACS Nano (2013) 7:9585-98. doi:10.1021/nn404473g

186. Maysinger D, Behrendt M, Lalancette-Hébert M, Kriz J. Real-time imaging of astrocyte response to quantum dots: in vivo screening model system for biocompatibility of nanoparticles. Nano Lett (2007) 7:2513-20. doi:10.1021/ nl071611t

187. Maysinger D, Hutter E. Nanoparticle-based caspase sensors. Nanomedicine (Lond) (2015) 10:483-501. doi:10.2217/nnm.14.158
188. Ding Y, Li J, Enterina JR, Shen Y, Zhang I, Tewson PH, et al. Ratiometric biosensors based on dimerization-dependent fluorescent protein exchange. Nat Methods (2015) 12:195-8. doi:10.1038/nmeth.3261

189. Kong L, Tang J, Little JP, Yu Y, Lämmermann T, Lin CP, et al. Continuous volumetric imaging via an optical phase-locked ultrasound lens. Nat Methods (2015) 12:759-62. doi:10.1038/nmeth.3476

190. Park J-H, Sun W, Cui M. High-resolution in vivo imaging of mouse brain through the intact skull. Proc Natl Acad Sci U S A (2015) 112:9236-41. doi:10.1073/pnas.1505939112

191. Govorunova EG, Sineshchekov OA, Janz R, Liu X, Spudich JL. Natural light-gated anion channels: a family of microbial rhodopsins for advanced optogenetics. Science (2015) 349:647-50. doi:10.1126/science.aaa7484

192. Deisseroth K. Optogenetics: 10 years of microbial opsins in neuroscience. Nat Neurosci (2015) 18:1213-25. doi:10.1038/nn.4091

193. Berndt A, Lee SY, Wietek J, Ramakrishnan C, Steinberg EE, Rashid AJ, et al. Structural foundations of optogenetics: determinants of channelrhodopsin ion selectivity. Proc Natl Acad Sci U S A (2016) 113:822-9. doi:10.1073/ pnas. 1523341113

194. Figueiredo M, Lane S, Tang F, Liu BH, Hewinson J, Marina N, et al. Optogenetic experimentation on astrocytes. Exp Physiol (2011) 96:40-50. doi:10.1113/expphysiol.2010.052597

195. Vazey EM, Aston-Jones G. New tricks for old dogmas: optogenetic and designer receptor insights for Parkinson's disease. Brain Res (2013) 1511:153-63. doi:10.1016/j.brainres.2013.01.021

196. Mao G, Qu F, St. Croix CM, Tyurina YY, Planas-Iglesias J, Jiang J, et al. Mitochondrial redox opto-lipidomics reveals mono-oxygenated cardiolipins as pro-apoptotic death signals. ACS Chem Biol (2016) 11:530-40. doi:10.1021/ acschembio. 5 b00737

197. Gregory AE, Titball R, Williamson D. Vaccine delivery using nanoparticles. Front Cell Infect Microbiol (2013) 3:13. doi:10.3389/fcimb.2013.00013

198. Dunkle A, Blanchette C, Boone T, Corzett M, Fischer N, Hoeprich P, et al. Co-delivery of adjuvant and subunit antigens via a nanoparticle platform induces tissue-associated and systemic adaptive immune responses (P4409). J Immunol (2013) 190:205.14.

199. Zhao L, Seth A, Wibowo N, Zhao C-X, Mitter N, Yu C, et al. Nanoparticle vaccines. Vaccine (2014) 32:327-37. doi:10.1016/j.vaccine.2013.11.069

Conflict of Interest Statement: The authors declare that the research was conducted in the absence of any commercial or financial relationships that could be construed as a potential conflict of interest.

Copyright (c) 2016 Maysinger and Zhang. This is an open-access article distributed under the terms of the Creative Commons Attribution License (CC BY). The use, distribution or reproduction in other forums is permitted, provided the original author(s) or licensor are credited and that the original publication in this journal is cited, in accordance with accepted academic practice. No use, distribution or reproduction is permitted which does not comply with these terms. 